\title{
Timed loaded standing in female chronic fatigue syndrome compared with other populations
}

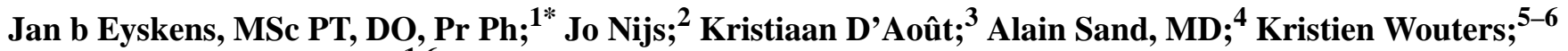 \\ Greta Moorkens, MD, $\mathbf{P h D}^{\mathbf{1 , 6}}$ \\ ${ }^{1}$ Department of Internal Medicine, Antwerp University Hospital, Antwerp, Belgium; ${ }^{2}$ Pain in Motion Research Group; \\ Departments of Human Physiology and Physiotherapy, Vrije Universiteit Brussel, Brussels, Belgium; and Department \\ of Physical Medicine and Physiotherapy, University Hospital Brussels, Brussels, Belgium; ${ }^{3}$ Department of Musculo- \\ skeletal Biology, Institute of Ageing and Chronic Disease, University of Liverpool, Liverpool, UK; Department of Biology, \\ University of Antwerp, Antwerp, Belgium; ${ }^{4}$ Nuclear Medicine, AZ Jan Palfijn, Ghent, Belgium; ${ }^{5}$ Department of Scientific \\ Coordination and Biostatistics, Antwerp University Hospital, Antwerp, Belgium; ${ }^{6}$ Faculty of Medicine and Health Sci- \\ ence, University of Antwerp, Antwerp, Belgium
}

\begin{abstract}
Patients with chronic fatigue syndrome (CFS), like patients with osteoporosis, have similar difficulties in standing and sitting. The aim of the study was to compare combined trunk and arm endurance among women with CFS $(n=72)$, women with osteoporosis $(n=30)$, nondisabled women $(n=55)$, and women from non-industrialized countries $(n=58)$ using the timed loaded standing (TLS) test. TLS measures how long a person can hold a $1 \mathrm{~kg}$ dumbbell in each hand in front of him or her with straight arms. TLS was higher in the industrialized nondisabled population than in the non-industrialized study population $(p<0.001)$ and in patients with osteoporosis $(p=0.002)$. TLS was lower in patients with CFS than in nondisabled controls $(p<$ 0.001). After adjusting for age, body height, and weight, combined trunk and arm endurance was lower in CFS patients than in osteoporotic patients, even though the patients with osteoporosis were more than 25 yr older $(p<0.001)$. In CFS, TLS was lower than in the non-industrialized group $(p=0.02)$. Since only women were studied, external validity of the results is limited to adult female patients with CFS. TLS revealed a specific biomechanical weakness in CFS patients that can be taken into account from the onset of a rehabilitation program. We propose that influencing the quality, rather than the quantity, of movement could be used in the rehabilitation.
\end{abstract}

Key words: chronic fatigue syndrome, deformation, endurance, graded exercise/exposure therapy, movement, nonindustrialized population, osteoporosis, physical performance, timed loaded standing, trunk.

Abstract corrected from original 11/5/15: Erratum in 52(7) JRRD 2015.

\section{INTRODUCTION}

Ongoing fatigue forms a major health problem in industrialized countries. Chronic fatigue syndrome (CFS) is defined by the U.S. Centers for Disease Control and Prevention as a condition characterized by self-reported unexplained persistent or relapsing fatigue of at least 6 mo duration and the concurrent occurrence of multiple nonspecific symptoms, including sore throat, muscle and joint pain, headache, tender cervical or axillary lymph nodes, unrefreshing sleep, and postexertional malaise [1].

Physical complaints as a result of military actionsespecially combat situations-are known from World War I on. Different terms—such as Da Costa syndrome, irritable heart, shell shock, neurocirculatory asthenia, and battle fatigue-have been used to coin the difficult to understand soldier's medical conditions following war situations [2]. More recently, the terms posttraumatic

\footnotetext{
Abbreviations: $\mathrm{BMI}=$ body mass index, $\mathrm{CFS}=$ chronic fatigue syndrome, TLS = timed loaded standing.

*Address all correspondence to Jan b Eyskens, MSc PT, DO, Pr Ph; Rijsenbergstraat 31, 9000 Ghent, Belgium; +32 4865070 01. Email: jan@beweging.org

http://dx.doi.org/10.1682/JRRD.2014.03.0086
} 
stress syndrome, and survivor's guilt syndrome have been used [3-4].

Chronic pain and fatigue form the core elements of the medical complaints, often described as idiopathic [5]. Solutions for these complaints have been searched for in the last decades. One of the most investigated postwar complaints is CFS. A sample of 23 participants showed that 43 percent met the CFS criteria [6-7].

Physical and psychological causes have been proposed to understand these complaints [8]. Most people with chronic pain and fatigue understand their condition to be physical in nature and are resistant to psychological theories [9-10]. In order to diminish the occurrence of these unexplained symptoms among veterans, more research is needed [5,11-12].

The amount of physical activity performed during daily life in CFS is lower than in nondisabled controls and seems to correlate with symptom severity and variability [13-16]. A systematic literature review revealed no definite conclusion in relation to physiological exercise capacity in patients with CFS [13]. Lower daily physical activity implies that patients with CFS might experience difficulties with certain activities like standing upright for a prolonged time. For humans, being upright (either standing or sitting) for a long, uninterrupted period of time is not how our bodies are built [17]. When a working task has to be executed, the active, muscular part of the spine has to function in a way that is not congruent with the nonrotatory recruitment of motor units [18].

Patients with CFS report difficulties being upright for a prolonged time, sometimes even after just a few minutes. Yet, studies examining the ability of patients with CFS to stay upright are essentially lacking. This is surprising because many daily activities require muscle endurance of the trunk to allow an upright position, often combined with upper-arm movements.

Shipp et al. used timed loaded standing (TLS), a measure of combined trunk and arm endurance in a population of women with osteoporosis complaining of similar physical inabilities [19]. Women with osteoporosis also show pronounced balance problems compared with women without osteoporosis [20]. They found moderately strong and statistically significant correlations between TLS and 16 of 18 measures of physical impairment and function in women with osteoporosis with known fractures. Functional reach distance, gait velocity, Medical Outcomes Study Short Form 36 Physical Function Subscale, shoulder flexion strength, and 6 min walk distance were most strongly associated with TLS time [19].

We used TLS in CFS $(n=72)$ and compared the results with nondisabled controls $(n=55)$ and patients with osteoporosis $(n=30)$ without known fractures. Living in an industrialized country could require different abilities and skills than living in a context without modern devices - almost all dependent on electricity — used to ease living, especially work. So we tested people in an environment that has not changed much over decades or generations, non-industrialized societies $(n=58$; 40 African and 18 Indian). These populations live in rural, agricultural societies in which nutrition and way of life (slower pace, no electricity, walking for transport, etc.) are different from in industrialized societies. In total, 215 participants were measured. The study aimed at examining whether TLS of women with CFS differs from nondisabled controls, nonindustrialized populations, and patients with osteoporosis.

\section{METHODS}

\section{Timed Loaded Standing Test}

TLS measures the time (in seconds) a person can stand while holding a $1 \mathrm{~kg}$ dumbbell in each hand with the arms at $90^{\circ}$ of shoulder flexion, elbows extended, and wrists in neutral pronation/supination. This is shown in Figure 1.

The TLS test is a physical performance measure of combined trunk and arm endurance simulating functional performance of the trunk in daily activities, most of which require the trunk to remain erect and stable while the upper limbs are used [19]. TLS has been shown to generate reliable data, with good intraclass correlation coefficients for same-day intertrial and 6 to $10 \mathrm{~d}$ testretest reliability in 127 women with osteoporosis with vertebral fractures [19]. TLS has been used for assessing combined trunk and arm endurance in people with vertebral osteoporosis.

\section{Participants and Populations}

In total, 215 individuals were measured, divided into four populations. The CFS population consisted of 72 female patients and was compared with 55 female nondisabled controls and 30 female patients with osteoporosis without known fractures. The study group from nonindustrialized countries, in total 58, consisted of 40 African and 18 Indian women. 


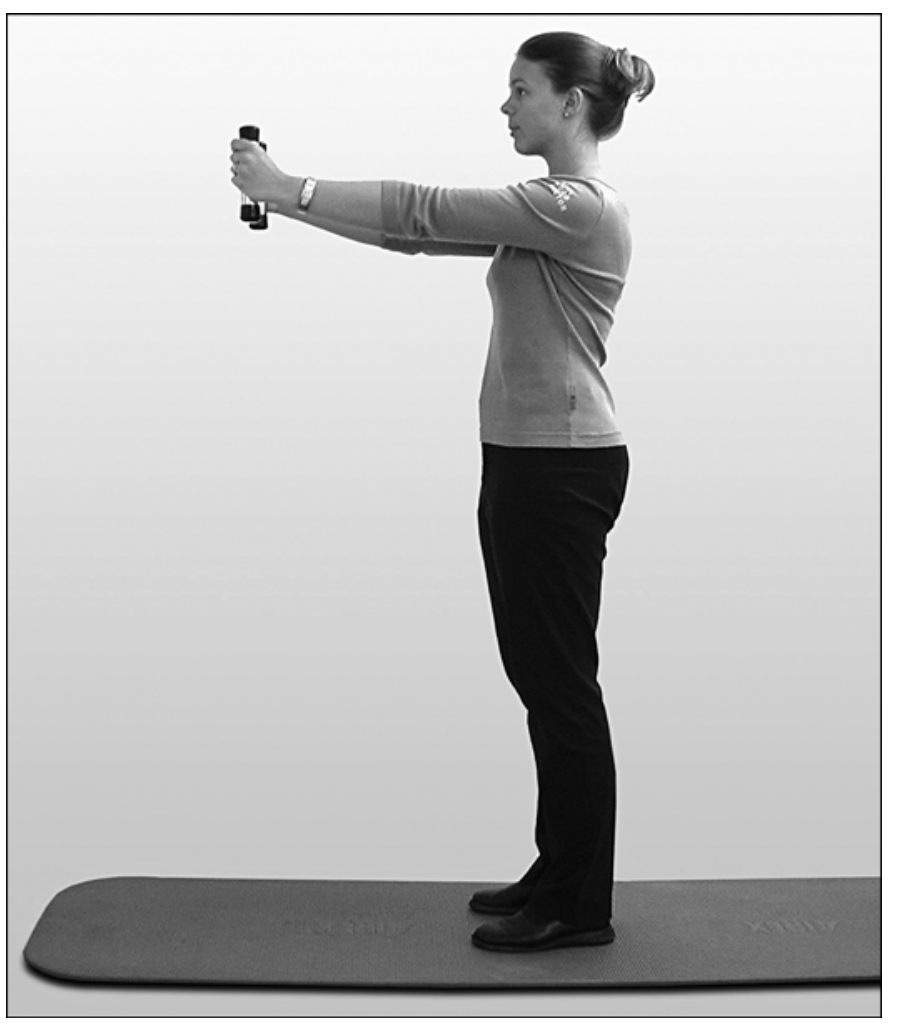

Figure 1.

Timed loaded standing test. For equipment and specific procedure, refer to Shipp et al. [19].

\section{Chronic Fatigue Syndrome Population}

One physician (G. Moorkens) from the Outpatient Clinic of General Internal Medicine at the Antwerp University Hospital, Belgium, recruited CFS patients fulfilling the 1994 Centers for Disease Control criteria [1]. The tested population included 72 adult Belgian women who were not pregnant (mean age $41 \mathrm{yr}$, range 20-56 yr) and had no major psychological comorbidity.

\section{Nondisabled Controls}

The nondisabled female controls $(n=55)$ consisted of nurses and physicians recruited from the participating hospitals (mean age $41 \mathrm{yr}$, range 31-48 yr). Study participants had not reported sick leave during the last 24 mo and were pain-free and without any (chronic) disease.

\section{Patients with Osteoporosis Without Known Fractures}

The population studied and measured consisted of women $(n=30)$ attending the nuclear medicine department, referred by other specialists for confirming the diag- nosis of osteoporosis (mean age $69 \mathrm{yr}$, range 60-78 yr). The diagnostic criteria for osteoporosis from the Belgian Health Institute, following the International Society of Densitometry, were used [21].

\section{Non-Industrialized Population}

An African and an Indian population were studied to have an idea of TLS in subjects unrelated to the culture and demands of industrialized countries. Those persons studied were not required to be upright for 16 uninterrupted hours in daily life, but could allow themselves very easily to lie down or to rest for a short or even longer period of time during the day. They were doing their regular daily activities in order to provide for their basic needs. All Indian and African participants were active in their communities.

Africa $(\boldsymbol{n}=\mathbf{4 0})$. All adult females (mean age $37 \mathrm{yr}$, range 17-72 yr) living in one compound were included. All lived in an agricultural community without any electricity available. The compound was linked to the rest of the environment (the village of Busura, Kombo Central, Western Division in the Gambia) with a single road. All TLS measurements in Africa were performed by the same researcher. When date of birth was unknown and age was reported, $0.5 \mathrm{yr}$ was added in order not to bias the averages too low.

India $(\boldsymbol{n}=\mathbf{1 8})$. Eighteen Indian women (mean age $39 \mathrm{yr}$, range 21-66 yr) were measured by the same researcher in the region of Bangalore, India, and in rural outposts (Mandya, Kolar Gold Fields). The region is very poor, most inhabitants are vegetarian, and the diet consist mainly of "staple food" (rice) [22]. All persons measured in this population reported never having worn shoes, or only in extremely rare cases (e.g., flip-flops, and then only worn as an adult when visiting the hospital). Subjects were asymptomatic adults. Also, prior to the recordings, personal data were collected: participants were weighed and their height was measured. The same correction was applied as in the African population when only age was reported.

\section{Study Design}

The study was designed as a case-controlled comparison, and the data collection took place at several locations. CFS and nondisabled controls were measured at the Outpatient Clinic of General Internal Medicine at the Antwerp University Hospital, Belgium. Patients with osteoporosis were measured at the Department of Nuclear Medicine, Jan Palfijn Hospital, Ghent, Belgium. The non-industrialized populations were measured in the Gambia and India. 
The study protocol was approved by the Ethics Committee of the University Hospital Antwerp. All potential study participants were informed about the study by a member of the research group, then asked to read an information leaflet. Next, written informed consent was obtained from all participants. After collecting information on personal characteristics and measuring participants' weight and height, the TLS test was completed. In order to prevent bias from pooling of sex data, only females were allowed to participate [13].

\section{Statistical Analysis}

Normality of data was checked for all parameters through quantile-quantile plots and Shapiro-Wilk test. Body height and surface area were distributed normally, but this was not the case for age, weight, body mass index (BMI), and TLS, even after log-transformation. Therefore, nonparametric tests were used.

Normally, distributed continuous variables are represented as mean with their standard deviation; for nonnormally distributed continuous variables, medians are given together with their lower and upper quartiles.

For comparing two groups, we used an unpaired $t$-test for normally distributed continuous variables and the
Mann-Whitney U test for non-normally distributed random variables or ordinal scores.

The difference in TLS between groups, controlling for differences in age, height, and weight, was determined by a general linear model. The square root of TLS has been used to obtain normality of the residuals. In the post hoc comparisons, the stepdown Bonferroni-Holm correction was used to adjust for multiple testing.

\section{RESULTS}

\section{Overview of Results}

An overview of the results can be found in the boxplot in Figure 2. No significant differences in TLS scores were measured between the African and Indian populations $(82.65 \pm 37.23$ vs $85.56 \pm 44.47$, respectively; $W=337$, $p=0.71)$. Therefore, both data sets were pooled.

The TLS in the four populations (nondisabled controls, non-industrialized, osteoporosis, and CFS populations) are plotted in Figure 2. Table 1 adds the statistical figures needed to underpin the boxplot.

More details are given in the next section comparing populations one by one.

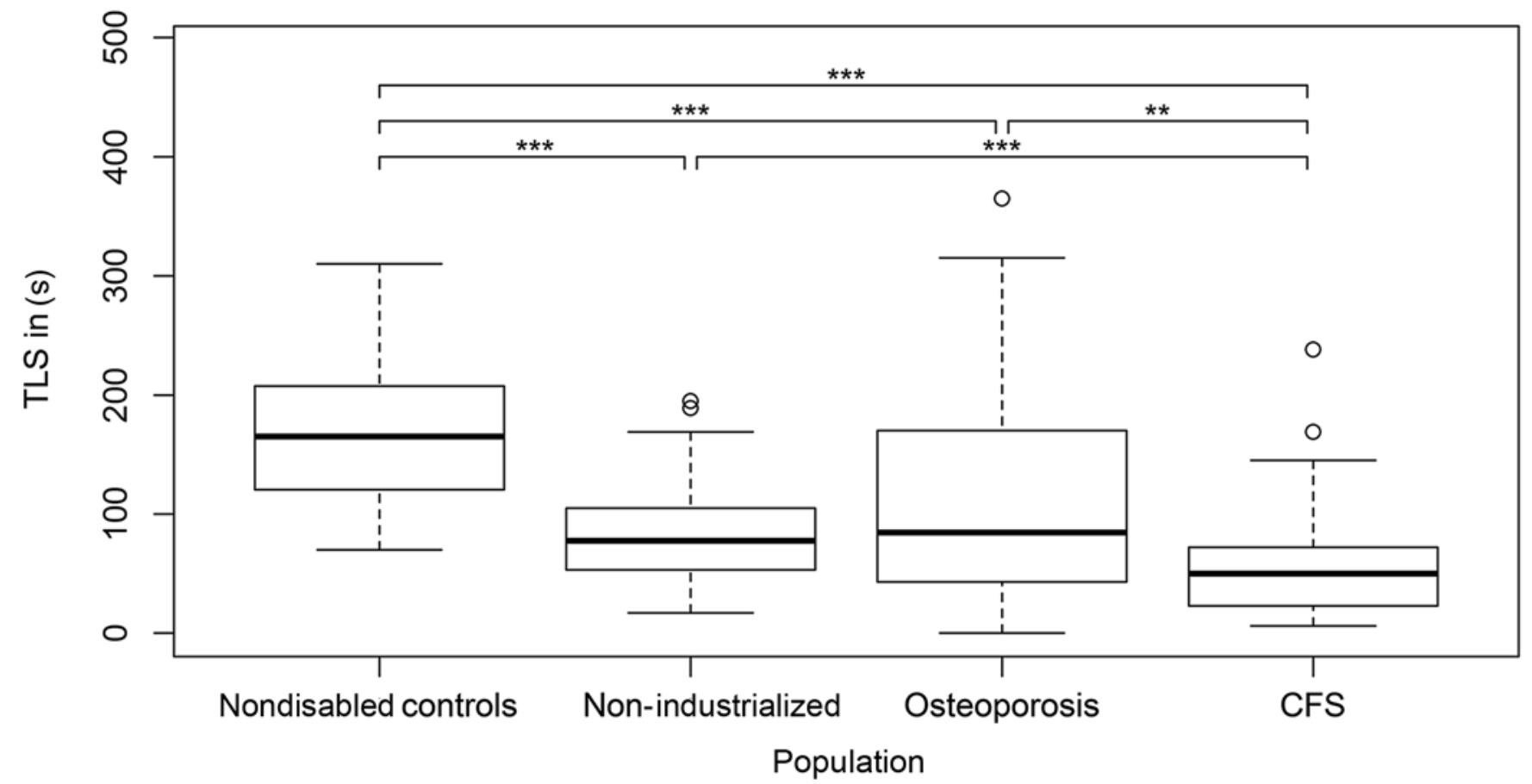

Figure 2.

Boxplot for timed loaded standing (TLS) for four populations. ${ }^{* \star} p<0.01 .{ }^{* \star *} p<0.001$. CFS $=$ chronic fatigue syndrome. 


\section{Comparing the Four Populations One by One}

\section{Nondisabled Industrialized Country Controls Versus} People from Non-Industrialized Countries

TLS, as well as body weight, height, and body surface area, were significantly lower in the non-industrialized populations studied than in the nondisabled controls. A linear regression model was used to compare TLS in an industrialized nondisabled population and a non-industrialized population, adjusted for age, body height, and weight (Table 2). TLS in the industrialized nondisabled population was higher than in the non-industrialized study population (Figure 2, Table 3, $p<0.001$ ).

\section{Nondisabled Controls Versus Osteoporosis Patients}

TLS was significantly shorter in patients with osteoporosis than in the nondisabled controls $(p<0.001)$.

After adjusting for the differences in age (significantly higher in osteoporotic patients), length, and weight (Table 2), we see a significantly longer TLS in nondis- abled controls than in the patients with osteoporosis (Table 3, $p=0.002$ ).

Patients with Osteoporosis Without Vertebral Fractures Versus Persons from Non-Industrialized Countries

Comparing our industrialized osteoporotic population without fractures to a non-industrialized population showed no significant difference in TLS results (Table 3).

Chronic Fatigue Syndrome Patients Versus Nondisabled Controls in an Industrialized Population

TLS was significantly lower in patients with CFS than in nondisabled controls (Figure 2, $p<0.001$ ). Patients with CFS were significantly smaller with a higher BMI than in the nondisabled controls (respectively $p=0.01$ and $p=0.03$ ). After adjusting for age, height, and weight (Table 2), a significant difference remained in TLS between nondisabled controls and CFS patients $(p<0.001$, linear regression model).

Table 1.

Data comparing different populations measured. Numbers are given as mean (range) unless otherwise stated.

\begin{tabular}{|c|c|c|c|c|}
\hline & Nondisabled Controls & Non-Industrialized & Osteoporosis & CFS \\
\hline $\bar{N}$ & 55 & 58 & 30 & 72 \\
\hline Age (yr) & $41(31-48)$ & $32(23-50)^{*}$ & $69(60-78)^{* * *+\dagger \dagger}$ & $43(32-48)^{\dagger+\# \#}$ \\
\hline Weight (kg) & $63(57-70)$ & $56(52-65)^{*}$ & $60(54-68)$ & $65(57-76)^{\dagger \dagger}$ \\
\hline Body Mass Index & $21.6(20.8-23.5)$ & 22.7 (20.4-26.6) & 23.7 (21.7-25.3) & $23.8(21.1-27.2)^{*}$ \\
\hline \multicolumn{5}{|c|}{$\begin{array}{l}{ }^{*} p<0.05,{ }^{* *} p<0.01,{ }^{* * *} p<0.001 \text { compared with nondisabled controls. } \\
{ }^{\dagger} p<0.05,{ }^{+\dagger} p<0.01,{ }^{\dagger+} p<0.001 \text { compared with people from non-industrialized countries. } \\
{ }^{\ddagger} p<0.05,{ }^{+\ddagger} p<0.01,{ }^{+\dagger} p<0.001 \text { compared with patients with osteoporosis. } \\
\text { CFS = chronic fatigue syndrome, SD = standard deviation, TLS = timed loaded standing. }\end{array}$} \\
\hline
\end{tabular}

Table 2.

Multiple linear regression model for timed loaded standing.

\begin{tabular}{|c|c|c|c|c|c|}
\hline & \multirow{2}{*}{ Estimate } & \multirow{2}{*}{ Standard Error } & \multicolumn{2}{|c|}{ 95\% Confidence interval } & \multirow{2}{*}{$\operatorname{Pr}(>|\mathbf{t}|)$} \\
\hline & & & Lower & Upper & \\
\hline Group (ref = nondisabled controls) & - & - & - & - & $<0.001$ \\
\hline Osteoporosis & & 0.78 & -4.46 & -1.36 & $<0.001$ \\
\hline CFS & & 0.51 & -6.81 & -4.79 & $<0.001$ \\
\hline Age (yr) & -0.02 & 0.02 & -0.05 & 0.01 & 0.27 \\
\hline Weight (kg) & 0.01 & 0.02 & -0.03 & 0.04 & 0.73 \\
\hline
\end{tabular}


Table 3.

Post hoc comparisons between different populations based on model in Table 2.

\begin{tabular}{lccc}
\hline & Estimate & Standard Error & $\boldsymbol{p}^{-V a l u e}$ \\
Non-Industrialized vs Nondisabled Controls & -4.22 & 0.61 & $<0.001$ \\
Osteoporosis vs Nondisabled Controls & -2.91 & 0.79 & 0.002 \\
Osteoporosis vs Non-Industrialized & 1.31 & 0.82 & 0.38 \\
Osteoporosis vs CFS & 2.89 & 0.75 & $<0.001$ \\
Non-Industrialized vs CFS & 1.58 & 0.54 & 0.02 \\
CFS vs Nondisabled controls & -5.80 & 0.51 & $<0.001$ \\
\hline
\end{tabular}

${ }^{*}$ With Bonferroni-Holm correction.

CFS = chronic fatigue syndrome.

Patients with Chronic Fatigue Syndrome Versus Patients with Osteoporosis

TLS was significantly lower in patients with CFS than in patients with osteoporosis (Figure 2, $p=0.003$ ). Also, patients with CFS were significantly larger, having a larger body surface area than patients with osteoporosis (respectively $p<0.001$ and $p=0.002$ ). After adjusting for age, body height, and weight (Table 2), the difference in TLS between patients with osteoporosis and patients with CFS was even more pronounced (Table 3, $p<$ $0.001)$.

\section{Patients with Chronic Fatigue Syndrome Versus Non- Industrialized Population}

Data on fatigue as a symptom in Africa and India are scarce and often related to infectious diseases and nutritional status. TLS was significantly lower in patients with CFS than in a non-industrialized population (Figure 2, $p<0.001$ ). CFS patients were significantly larger and had a higher weight and greater body surface area than the volunteers from non-industrialized countries (respectively $p<0.001, p=0.003$ and $p<0.001$ ).

After adjusting for age, body height, weight, and surface, we found a significantly lower TLS in CFS patients than in the non-industrialized group (Table 3, $p=0.02$ ).

\section{DISCUSSION}

With respect to standing upright and physical activity, CFS patients have a similar problem as patients with osteoporosis: it is difficult for both populations to keep their spines vertical. Women with osteoporosis with vertebral fractures who endorsed having back tiredness when standing and working with the arms in front of the body, sitting to rest because of back tiredness or pain, and planning rest periods because of back tiredness or pain had significantly lower TLS times, supporting the validity of the TLS data.

This is the first study of combined trunk and arm endurance testing in various study populations, including CFS. The TLS test revealed a specific biomechanical weakness in CFS patients. This weakness became apparent when comparing TLS in CFS with the other populations measured. TLS in CFS was much shorter than in patients with osteoporosis who were more than 25 yr older.

TLS results in both non-industrialized societies were much lower than in nondisabled industrialized controls, and although being more than $30 \mathrm{yr}$ younger, people from the non-industrialized groups performed the test for a shorter period of time than osteoporotic patients from industrialized nations.

The complaints of patients affected by CFS may be understood in relation to the short TLS and their apparent weakness in holding their spines upright, especially for a prolonged time, be it in a sitting position, a standing position, or when walking.

CFS patients' complaints of reduced exercise capacity and/or of perceived greater effort during exercise can be linked to the fact that less muscle strength has been found in CFS. Both deconditioning and central factors have been used to explain this muscular weakness in CFS [23-24].

Patients with CFS not only are weaker from a muscular point of view but also show an inability to sustain target activity levels [25]. Gait in patients with CFS shows abnormalities when compared with sedentary controls [26]. Physiological cost of walking in CFS is greater than in nondisabled subjects [27-28]. During treadmill walking, a subtle abnormality in vagal activity was noticed that could explain, in part, postexertion symptom exacerbation [29]. Female patients with CFS's aerobic power indicates a low normal fitness level without cardiopulmonary 
abnormality [30]. Patients with CFS are weaker than sedentary and depressed controls but also as unfit as sedentary controls [23]. Female CFS patients' aerobic power indicates a low normal fitness level without cardiopulmonary abnormality [30].

Regarding working status, the majority of participants at a trial remained functionally impaired over time and stayed unemployed at follow-up [31].

In a review on this topic, Nijs et al. wrote the following: "Patients with CFS perform less physical activity during daily life, and have less peak isometric muscle strength compared to healthy sedentary control subjects." This review concluded that the available data point toward a reduced physiological exercise capacity in CFS [13].

Comparing our data with previous findings is impossible because previous studies in the field of physical performance measurements in CFS have used other measures with less ecological validity, like muscle strength and exercise performance testing [13,32-34]. Further research could help us to understand the fundamentals of these finding. It can therefore be considered, from the very onset of rehabilitation, to take into account the low endurance of patients with CFS to resist gravity when upright.

Finally, a few methodological issues regarding the present study have to be mentioned. Since only women were studied, external validity of the results is limited to adult female patients with CFS. A few parameters of the included participants were not taken into account, such as menopausal state, level of education, and intelligence. And as usual, longitudinal data are required to examine the stability of these findings in a condition such as CFS, which is characterized by high health status fluctuations over time.

The sample size of this study was of sufficient power and used a measurement that has proven validity for measuring trunk and arm endurance. The TLS test has been shown to generate reliable data, but its true validity remains to be examined, including comparison with a gold standard.

\section{CONCLUSIONS}

Women with CFS have lower combined trunk and arm muscle endurance than nondisabled controls, nonindustrialized populations, and osteoporotic patients. The TLS might be useful for assessing low combined trunk arm endurance in women with CFS. Further studying of the nature and etiology of the decreased combined trunk and arm muscle endurance in CFS patients is warranted. In addition, studies examining whether specific exercise interventions are able to restore the specific weakness found here are necessary.

\section{ACKNOWLEDGMENTS}

\section{Author Contributions:}

Study concept and design: J. b Eyskens, J. Nijs. Acquisition of data: J. b Eyskens, A. Sand, K. D’Août. Analysis and interpretation of data: J. b Eyskens.

Drafting of manuscript: J. b Eyskens, J. Nijs.

Critical revision of manuscript for important intellectual content:

G. Moorkens, K. Wouters, J. Nijs.

Statistical analysis: K. Wouters.

Study supervision: G. Moorkens.

Financial Disclosures: The authors have declared that no competing interests exist.

Funding/Support: This study was unfunded at the time of manuscript preparation.

Additional Contributions: Suggestions and advice have been given to all of us during the process of developing this article. We thank all for their help but especially wish to mention Bart Leroy, MD, and Hugo Stuer, MD, for the many hours discussing chronic fatigue in a transdisciplinary way. We also want to thank Stephan Praet, $\mathrm{MD}, \mathrm{PhD}$, for his remarks regarding the article as it evolved. Without the help of Marie Ielegems, social worker, for testing populations in Africa, we would not be able to compare our industrialized data with non-industrialized data.

Institutional Review: The study protocol was approved by the Ethics Committee of the University Hospital Antwerp and written informed consent was obtained from all study participants.

Participant Follow-Up: The authors plan to inform participants, for whom contact information is available, of the publication of this study.

\section{REFERENCES}

1. Fukuda K, Straus SE, Hickie I, Sharpe MC, Dobbins JG, Komaroff A; International Chronic Fatigue Syndrome Study Group. The chronic fatigue syndrome: A comprehensive approach to its definition and study. Ann Intern Med. 1994;121(12):953-59. [PMID:7978722] http://dx.doi.org/10.7326/0003-4819-121-12-199412150$\underline{00009}$

2. Honig AL. War then and now: From surviving to thriving. Int J Emerg Ment Health. 2010;12(3):207-12. [PMID:21473371]

3. Pearn J. Traumatic stress disorders: A classification with implications for prevention and management. Mil Med. 2000;165(6):434-40. [PMID:10870357]

4. Kang HK, Li B, Mahan CM, Eisen SA, Engel CC. Health of US veterans of 1991 Gulf War: A follow-up survey in 
10 years. J Occup Environ Med. 2009;51(4):401-10. [PMID:19322107] http://dx.doi.org/10.1097/JOM.0b013e3181a2feeb

5. Engel CC, Jaffer A, Adkins J, Riddle JR, Gibson R. Can we prevent a second 'Gulf War syndrome'? Population-based healthcare for chronic idiopathic pain and fatigue after war. Adv Psychosom Med. 2004;25:102-22. [PMID:15248370] http://dx.doi.org/10.1159/000079061

6. Lincoln AE, Helmer DA, Schneiderman AI, Li M, Copeland HL, Prisco MK, Wallin MT, Kang HK, Natelson BH. The war-related illness and injury study centers: A resource for deployment-related health concerns. Mil Med. 2006; 171(7):577-85. [PMID:16895119]

7. Fiedler N, Lange G, Tiersky L, DeLuca J, Policastro T, Kelly-McNeil K, McWilliams R, Korn L, Natelson B. Stressors, personality traits, and coping of Gulf War veterans with chronic fatigue. J Psychosom Res. 2000;48(6): 525-35. [PMID:11033371] http://dx.doi.org/10.1016/S0022-3999(00)00088-X

8. Shively SB, Perl DP. Traumatic brain injury, shell shock, and posttraumatic stress disorder in the military-past, present, and future. J Head Trauma Rehabil. 2012;27(3): 234-39. [PMID:22573042] http://dx.doi.org/10.1097/HTR.0b013e318250e9dd

9. Kilshaw S. Gulf war syndrome: A reaction to psychiatry's invasion of the military? Cult Med Psychiatry. 2008;32(2): 219-37. [PMID:18363083] http://dx.doi.org/10.1007/s11013-008-9088-0

10. Lange G, Tiersky L, DeLuca J, Peckerman A, Pollet C, Policastro T, Scharer J, Ottenweller JE, Fiedler N, Natelson BH. Psychiatric diagnoses in Gulf War veterans with fatiguing illness. Psychiatry Res. 1999;89(1):39-48. [PMID:10643876] http://dx.doi.org/10.1016/S0165-1781(99)00095-5

11. Hyams KC, Wignall FS, Roswell R. War syndromes and their evaluation: From the U.S. Civil War to the Persian Gulf War. Ann Intern Med. 1996;125(5):398-405. [PMID:8702091] http://dx.doi.org/10.7326/0003-4819-125-5-199609010$\underline{00007}$

12. Rumage C, Falca-Dodson M, Santos SL, Teichman R. Medically unexplained symptoms in the veteran population: Challenges and opportunities. MD Advis. 2011;4(2): 34-36. [PMID:21637181]

13. Nijs J, Aelbrecht S, Meeus M, Van Oosterwijck J, Zinzen E, Clarys P. Tired of being inactive: A systematic literature review of physical activity, physiological exercise capacity and muscle strength in patients with chronic fatigue syndrome. Disabil Rehabil. 2011;33(17-18):1493-1500.

[PMID:21166613] http://dx.doi.org/10.3109/09638288.2010.541543

14. Sargent C, Scroop GC, Nemeth PM, Burnet RB, Buckley JD. Maximal oxygen uptake and lactate metabolism are normal in chronic fatigue syndrome. Med Sci Sports Exerc. 2002;34(1):51-56. [PMID:11782647]

http://dx.doi.org/10.1097/00005768-200201000-00009

15. van Weering M, Vollenbroek-Hutten MM, Kotte EM, Hermens HJ. Daily physical activities of patients with chronic pain or fatigue versus asymptomatic controls. A systematic review. Clin Rehabil. 2007;21(11):1007-23.

[PMID:17984153]

http://dx.doi.org/10.1177/0269215507078331

16. Meeus M, van Eupen I, van Baarle E, De Boeck V, Luyckx A, Kos D, Nijs J. Symptom fluctuations and daily physical activity in patients with chronic fatigue syndrome: A casecontrol study. Arch Phys Med Rehabil. 2011;92(11):1820-26. [PMID:22032215] http://dx.doi.org/10.1016/j.apmr.2011.06.023

17. Zennaro D, Läubli T, Krebs D, Klipstein A, Krueger H. Continuous, intermitted and sporadic motor unit activity in the trapezius muscle during prolonged computer work. J Electromyogr Kinesiol. 2003;13(2):113-24.

[PMID:12586517] http://dx.doi.org/10.1016/S1050-6411(02)00066-4

18. Hägg GM, Suurküla J. Zero crossing rate of electromyograms during occupational work and endurance tests as predictors for work related myalgia in the shoulder/neck region. Eur J Appl Physiol Occup Physiol. 1991;62(6): 436-44. [PMID:1893908] http://dx.doi.org/10.1007/BF00626617

19. Shipp KM, Purse JL, Gold DT, Pieper CF, Sloane R, Schenkman M, Lyles KW. Timed loaded standing: A measure of combined trunk and arm endurance suitable for people with vertebral osteoporosis. Osteoporos Int. 2000; 11(11):914-22. [PMID:11193243] http://dx.doi.org/10.1007/s001980070029

20. Abreu DC, Trevisan DC, Costa GC, Vasconcelos FM, Gomes MM, Carneiro AA. The association between osteoporosis and static balance in elderly women. Osteoporos Int. 2010;21(9):1487-91. [PMID:19936868] http://dx.doi.org/10.1007/s00198-009-1117-5

21. Hans D, Downs RW Jr, Duboeuf F, Greenspan S, Jankowski LG, Kiebzak GM, Petak SM; International Society for Clinical Densitometry. Skeletal sites for osteoporosis diagnosis: The 2005 ISCD Official Positions. J Clin Densitom. 2006;9(1):15-21.

22. D’Août K, Pataky TC, De Clercq D, Aert P. The effects of habitual footwear use: Foot shape and function in native barefoot walkers. Footwear Science. 2009;1(2):81-94. http://dx.doi.org/10.1080/19424280903386411

23. Fulcher KY, White PD. Strength and physiological response to exercise in patients with chronic fatigue syndrome. J Neurol Neurosurg Psychiatry. 2000;69(3):302-7. [PMID:10945803] http://dx.doi.org/10.1136/jnnp.69.3.302 
24. Kent-Braun JA, Sharma KR, Weiner MW, Massie B, Miller RG. Central basis of muscle fatigue in chronic fatigue syndrome. Neurology. 1993;43(1):125-31.

[PMID:8423875] http://dx.doi.org/10.1212/WNL.43.1 Part 1.125

25. Black CD, McCully KK. Time course of exercise induced alterations in daily activity in chronic fatigue syndrome. Dyn Med. 2005;4:10. [PMID:16255779] http://dx.doi.org/10.1186/1476-5918-4-10

26. Boda WL, Natelson BH, Sisto SA, Tapp WN. Gait abnormalities in chronic fatigue syndrome. J Neurol Sci. 1995; 131(2):156-61. [PMID:7595641] http://dx.doi.org/10.1016/0022-510X(95)00108-E

27. Paul L, Rafferty D, Marshal R. Physiological cost of walking in those with chronic fatigue syndrome (CFS): A casecontrol study. Disabil Rehabil. 2009;31(19):1598-1604. [PMID:19848558] http://dx.doi.org/10.1080/09638280802652015

28. Paul L, Rafferty D, Wood L, Maclaren W. Gait characteristics of subjects with chronic fatigue syndrome and controls at self-selected and matched velocities. J Neuroeng Rehabil. 2008;5:16. [PMID:18505580] http://dx.doi.org/10.1186/1743-0003-5-16

29. Cordero DL, Sisto SA, Tapp WN, LaManca JJ, Pareja JG, Natelson BH. Decreased vagal power during treadmill walking in patients with chronic fatigue syndrome. Clin Auton Res. 1996;6(6):329-33. [PMID:8985621] http://dx.doi.org/10.1007/BF02556303

30. Sisto SA, LaManca J, Cordero DL, Bergen MT, Ellis SP, Drastal S, Boda WL, Tapp WN, Natelson BH. Metabolic and cardiovascular effects of a progressive exercise test in patients with chronic fatigue syndrome. Am J Med. 1996; 100(6):634-40. [PMID:8678084] http://dx.doi.org/10.1016/S0002-9343(96)00041-1

31. Tiersky LA, DeLuca J, Hill N, Dhar SK, Johnson SK, Lange G, Rappolt G, Natelson BH. Longitudinal assessment of neuropsychological functioning, psychiatric status, functional disability and employment status in chronic fatigue syndrome. Appl Neuropsychol. 2001;8(1):41-50. [PMID:11388123] http://dx.doi.org/10.1207/S15324826AN0801_6

32. Wyller VB, Saul JP, Walløe L, Thaulow E. Sympathetic cardiovascular control during orthostatic stress and isometric exercise in adolescent chronic fatigue syndrome. Eur J Appl Physiol. 2008;102(6):623-32. [PMID:18066580] http://dx.doi.org/10.1007/s00421-007-0634-1

33. Ickmans K, Meeus M, De Kooning M, Lambrecht L, Pattyn $\mathrm{N}$, Nijs J. Can recovery of peripheral muscle function predict cognitive task performance in chronic fatigue syndrome with and without fibromyalgia? Phys Ther. 2014;94(4):511-22. [PMID:24363336]

34. Ickmans K, Meeus M, De Kooning M, Lambrecht L, Nijs J. Recovery of upper limb muscle function in chronic fatigue syndrome with and without fibromyalgia. Eur J Clin Invest. 2014;44(2):153-59. [PMID:24313704] http://dx.doi.org/10.1111/eci.12201

Submitted for publication March 27, 2014. Accepted in revised form November 14, 2014.

This article and any supplementary material should be cited as follows:

Eyskens JB, Nijs J, D’Août K, Sand A, Wouters K, Moorkens G. Timed loaded standing in female chronic fatigue syndrome compared with other populations. J Rehabil Res Dev. 2015;52(1):21-30.

http://dx.doi.org/10.1682/JRRD.2014.03.0086

ResearcherID: Jan b Eyskens, MSc PT, DO, Pr Ph: B8552-2015; Jo Nijs: B-3336-2011; Greta Moorkens, MD, PhD: B-8776-2015

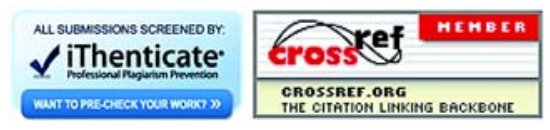


